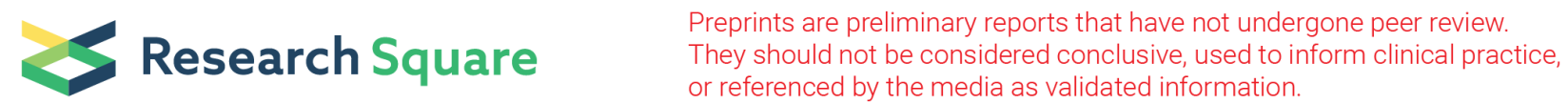

\section{Predictors of changes in skeletal muscle mass after esophagectomy in elderly patients with esophageal cancer}

\section{Tsuyoshi Harada ( $\nabla$ tsuyoshi6167@gmail.com )}

National Cancer Center Higashi Hospital: Kokuritsu Gan Center Higashi Byoin https://orcid.org/00000003-4459-8262

\section{Noriatsu Tatematsu}

Nagoya University: Nagoya Daigaku

Junya Ueno

National Cancer Center-Hospital East: Kokuritsu Gan Center Higashi Byoin

\section{Yu Koishihara}

National Cancer Center-Hospital East: Kokuritsu Gan Center Higashi Byoin

Nobuko Konishi

National Cancer Center-Hospital East: Kokuritsu Gan Center Higashi Byoin

\section{Takuya Fukushima}

National Cancer Center Hospital: Kokuritsu Gan Kenkyu Center Chuo Byoin

Hisashi Fujiwara

National Cancer Center-Hospital East: Kokuritsu Gan Center Higashi Byoin

Takeo Fujita

National Cancer Center-Hospital East: Kokuritsu Gan Center Higashi Byoin

\section{Ayako Wada}

Keio University: Keio Gijuku Daigaku

\section{Tetsuya Tsuji}

Keio University: Keio Gijuku Daigaku https://orcid.org/0000-0002-4728-9409

\section{Research Article}

Keywords: Esophageal cancer, Esophagectomy, Skeletal muscle mass, Elderly patients

Posted Date: March 15th, 2021

DOl: https://doi.org/10.21203/rs.3.rs-213862/v1

License: (a) (i) This work is licensed under a Creative Commons Attribution 4.0 International License. Read Full License 


\section{Abstract}

Purpose : Although a change in skeletal muscle mass index (SMI) 4 months after esophagectomy impacts prognosis, predictors of a change in SMI have not been revealed. The purpose of this exploratory retrospective study was to clarify the predictors of a change in SMI after curative esophagectomy in elderly patients with esophageal cancer.

Methods : Fifty-four patients who underwent esophagectomy and perioperative rehabilitation from 2015 to 2018 were enrolled. Preoperative and postoperative SMI (cm 2 /m 2 ) were calculated using computed tomography images. The ratio change in SMI was calculated as follows: (postoperative SMI preoperative SMI $\div$ preoperative SMI $\times 100 \%$. Potential predictors of a change in SMI ratio were analyzed by multiple regression.

Results : The mean ratio change in SMI 4 months after esophagectomy was $-7.1 \% \pm 9.4 \%$. The ratio change in quadriceps muscle strength in the first month after surgery ([postoperative strength preoperative strength] $\div$ preoperative strength $\times 100 \%$ ) (standardized $\beta=.273, p=.038$ ) and neoadjuvant chemotherapy (NAC) (standardized $\beta=.398, p=.006$ ) were predictors of the ratio change in SMI independent of age, sex, pathological stage, and preoperative SMI.

Conclusion : Quadriceps muscle weakness in the first month after esophagectomy and NAC were predictors of the ratio change in SMI after esophagectomy. Continuous postoperative comprehensive rehabilitation and supportive care may inhibit loss of skeletal muscle mass.

\section{Introduction}

The 5-year survival rates of patients with clinical stage II and III esophageal cancer (Union for International Cancer Control tumor-node-metastasis [UICC-TNM] classification, $6^{\text {th }}$ edition) after esophagectomy are approximately $65 \%$ and $40 \%$ [1], respectively. This type of cancer has a poor prognosis compared with other cancers. The number of elderly patients with esophageal cancer (aged over 70 years) is increasing, and these patients have a poor prognosis after esophagectomy [2-5].

Skeletal muscle mass at pretreatment is an important factor for prognosis in elderly patients with solid tumors, including esophageal cancer [6, 7]. In patients with esophageal cancer, a change in skeletal muscle mass index (SMI) within 6 months after esophagectomy is an important factor for overall survival, independent of pretreatment $\operatorname{SMI}[4,8,9]$. A change in skeletal muscle mass is generally associated with four factors: aging, disease, physical function, and nutrition [10-14]. In fact, previous studies reveal that patients with advanced pathological tumor stage and abundant preoperative SMI have a marked loss of skeletal muscle mass 4 months after esophagectomy $[4,9]$. However, no studies have investigated the impact of reversible factors, such as physical function and nutrition, on the change in skeletal muscle mass in elderly patients with esophageal cancer after esophagectomy. If reversible factors, such as physical function and nutrition, are predictors of postoperative changes in skeletal 
muscle mass in elderly patients with esophageal cancer, appropriate rehabilitation, including exercise and nutrition, may prevent critical loss of skeletal muscle mass and improve prognosis after esophagectomy.

This study aimed to clarify predictors of a change in skeletal muscle mass after curative esophagectomy in elderly patients with esophageal cancer, including indicators of physical function and nutrition.

\section{Methods}

\section{Design and participants}

This study was a retrospective cohort study. Subjects were over 70 years of age and had undergone curative esophagectomy for esophageal cancer at the National Cancer Center East Hospital between September 2015 and December 2018. The inclusion criteria were as follows: 1) completion of physical function and nutritional assessments; 2) computed tomography (CT) within 2 months prior to and $4 \pm 2$ months after esophagectomy. The exclusion criteria were as follows: 1 ) readmission, death, or recurrence by the day of postoperative $\mathrm{CT}$; 2) distant metastasis at esophagectomy; 3 ) untreated or undertreated duplicate cancer; 4) missing data. Informed consent was obtained through an opt-out consent process due to the retrospective nature of the study. This study was approved by the research ethics committee of the National Cancer Center (2019-075) in accordance with the Declaration of Helsinki.

\section{Perioperative rehabilitation}

Perioperative rehabilitation was performed on all subjects. Preoperative rehabilitation is a home-based intervention, consisting of respiratory training with incentive spirometry; resistance training, such as squats and heel-lift exercises; and aerobic exercise with walking. Postoperative rehabilitation was performed from the first postoperative day at an intensive care unit up until discharge for 20-40 minutes per day, including early mobilization, respiratory training, resistance training, and aerobic exercise depending on the individual's condition.

\section{Assessment}

\section{Patient characteristics}

We obtained patient characteristics from medical records, and the variables assessed were as follows: age, sex, neoadjuvant chemotherapy (NAC), preoperative C-reactive protein ( $\geq 0.5 \mathrm{mg} / \mathrm{dL}$ vs. $<0.5 \mathrm{mg} / \mathrm{dL})$ [15], neutrophil-lymphocyte ratio ( $\geq 3.5$ vs. $<3.5$ ) [16], pathological UICC-TNM classification $7^{\text {th }}$ edition [17] (pT 3/1-2, pN positive/negative, and pStage III/I-II [4]), presence of postoperative complications, including pneumonia and anastomotic leak ( $\geq$ I according to Japan Clinical Oncology Group 
postoperative complications criteria in line with the Clavien-Dindo classification [18]), and length of hospital stay ( $\geq$ median vs. <median).

\section{Physical function and nutrition}

Preoperative and postoperative physical function, including isometric quadriceps muscle strength (QS) (IsoForce GT-330, OG GIKEN, Japan) [19], usual gait speed of 4 meters [20], preoperative and postoperative nutrition (prognostic nutrition index [PNI] [21]), and body mass index (BMI), were collected from medical records. For isometric QS, the side with a greater muscle strength was analyzed. Physical function and nutrition were measured within 3 months before esophagectomy and at the first visit after discharge (within the first month after discharge). In the variables of physical function and nutrition, the change ratio (\%) after esophagectomy was calculated as follows: (postoperative value - preoperative value) $\div$ preoperative value $\times 100 \%$.

\section{Ratio change in SMI}

We used SMI [24], which was calculated from CT images at the level of L3, as an indicator of skeletal muscle mass. CT was performed twice within 3 months prior to and $4 \pm 2$ months after esophagectomy. Regarding preoperative CT images, CT images after NAC were used if the patient was treated with NAC. The cross-sectional area of the Hounsfield unit (-29 to 150) at the level of $L 3$ on axial CT images was measured in the skeletal muscle area using SliceOmatic (Imagelabo, Canada) [22]. SMI was calculated as follows: cross-sectional skeletal muscle area $\div\left(\right.$ height $\left.^{2}\right)[4,5,8,9,22]$. The ratio change of SMI was calculated as follows: $[($ post-SMI - pre-SMI) $\div$ pre-SMI] $\times 100 \%[4,8,9]$.

\section{Statistics}

Descriptive statistics are presented as number of people and mean \pm standard deviation. The difference in SMI before, compared with after, esophagectomy was analyzed with a paired t-test. With a univariate analysis, associations between the ratio change in SMI and physical function, nutrition, and patient characteristics were analyzed with simple linear regression. Multiple regression was performed using the forced entry method. The dependent variable was the ratio change in SMI. Explanatory variables were potential predictors of a ratio change in SMI with significance in a univariate analysis. Confounding variables were age, sex, preoperative SMI [9], and pStage [4]. A stratified analysis for SMI was performed using these predictors. Patients were divided into two groups with a median value as a cut-off point if the predictor was a continuous variable. Differences in preoperative and postoperative SMI between the two 
groups were compared with one-way analysis of variance adjusted using the Bonferroni method. Then, the association of predictors with other factors was analyzed using logistic regression. Statistical significance was considered as a two-tailed $p$ value of $<0.05$. All analyses were performed with SPSS version 26 (IBM Corp., Japan) for Windows. Linear regression was drawn using R version 4.0.2 (R Foundation for Statistical Computing, Vienna, Austria).

\section{Results}

\section{Patient characteristics}

A total of 54 patients were analyzed (Figure 1). The mean age was $75.3 \pm 3.6$ years, and the number of males was 42 (78\%). There was a significant difference between preoperative SMI $\left(40.3 \pm 7.7 \mathrm{~cm}^{2} / \mathrm{m}^{2}\right)$ and postoperative SMI $\left(37.3 \pm 7.4 \mathrm{~cm}^{2} / \mathrm{m}^{2}\right)(\mathrm{p}<0.001)$. The mean ratio change in SMI was $-7.1 \% \pm 9.4 \%$ (Table 1). Regarding the timing of assessments, the mean number of months of preoperative and postoperative CT scans were $1.3 \pm 0.6$ months before and $4.1 \pm 0.6$ months after esophagectomy. The mean days of preoperative and postoperative physical function and BMI were $4.9 \pm 7.5$ days before and $36.4 \pm 12.8$ days after esophagectomy. The mean days of preoperative and postoperative PNI were $3.6 \pm$ 2.8 days before and $33.9 \pm 9.3$ days after esophagectomy.

\section{Predictors of a change in SMI}

Multiple regression analysis showed that the ratio change in QS in the first month after esophagectomy (standardized $\beta=0.274, p=0.038$ ) and NAC (standardized $\beta=0.387, p=0.008$ ) was a predictor of the ratio change in SMI, independent of sex, age, preoperative SMI, and pStage (Figure 2, Table 2). The coefficient of determination $\left(R^{2}\right)$ of the model was 0.26 . With a stratified analysis, patients with a marked decline in QS tended to have a lower SMI 4 months after esophagectomy, compared with patients with less of a decline. We defined the median value $(-9.9 \%)$ as the cut-off point $\left(36.3 \pm 8.0 \mathrm{~cm}^{2} / \mathrm{m}^{2} \mathrm{vs} .38 .4 \pm\right.$ $6.8 \mathrm{~cm}^{2} / \mathrm{m}^{2}$, Figure 3). There was a significant difference between patients treated with NAC versus those treated without NAC in preoperative SMI (Figure 3). In addition, patients treated with NAC tended to have a lower SMI 4 months after esophagectomy, compared with patients treated without NAC (36.4 \pm 7.7 $\mathrm{cm}^{2} / \mathrm{m}^{2}$ vs. $38.4 \pm 7.1 \mathrm{~cm}^{2} / \mathrm{m}^{2}$, Figure $3 \mathrm{~b}$ ).

\section{Association of predictors with other factors}

The massive decline in QS in the first month after surgery (ratio change, $\leq-9.9 \%$ ) was significantly associated with a postoperative change in usual gait speed (odds ratio, 0.955, $p=0.032$ ) and a longer length of hospital stay ( $\geq 18.5$ days) (odds ratio, $4.000, p=0.016$ ) (Table 3 ). NAC was significantly 
associated with preoperative BMI (odds ratio, $0.818, \mathrm{p}=0.047$ ) and preoperative SMI (odds ratio, 0.907, $\mathrm{p}$ $=0.017)($ Table 3$)$.

\section{Discussion}

The present study investigated predictors of a change in skeletal muscle mass after curative esophagectomy in 54 elderly patients with esophageal cancer aged over 70 years. The mean ratio change in SMI 4 months after esophagectomy was $-7.1 \% \pm 9.4 \%$. From the multiple regression analysis, a change in QS in the first month after esophagectomy and NAC were predictors for a change in SMI 4 months after esophagectomy.

A decline in isometric QS in the first month after esophagectomy was a significant predictor for loss of SMI 4 months after esophagectomy (Table 2, Figure 2). Previous large cohort studies report that a change in muscle strength precedes a change in skeletal muscle mass in community-dwelling older adults $[13,14]$. Our results in elderly patients with esophageal cancer support these previous studies. Regarding recovery of QS after esophagectomy, QS significantly improved from the first month to 3 months after surgery in patients with esophageal cancer [24]. Therefore, due to diversity in QS recovery after esophagectomy, changes in QS in the first month after esophagectomy may be predictive of a decrease in SMI 4 months after surgery.

Moreover, a decline in QS in the first month after esophagectomy was associated with a decline in usual gait speed and a long length of hospital stay in our study (Table 3). Previous studies have shown that QS and gait speed are associated with physical activity $[25,26]$. Hence, the change in QS in the first month after esophagectomy may be impacted by physical activity [27-29] before and after discharge. In addition, because physical function is impacted by postoperative complications [24] and physical symptoms [30], a decline in QS may be associated with a long length of hospital stay. Therefore, continuous rehabilitation combined with perioperative supportive care for improving physical activity, preventing complications, and inhibiting symptoms may improve prognosis by preventing loss of skeletal muscle mass in elderly patients with esophageal cancer.

In our study, NAC was a significant predictor for less marked loss of SMI 4 months after esophagectomy. Patients treated with NAC were significantly associated with a lower preoperative SMI and BMI (Table 3) and had a significantly lower preoperative SMI compared with patients who did not receive NAC (Figure 3). NAC reduced skeletal muscle mass by approximately $3 \%$ because of side effects, such as fatigue, loss of appetite, and decreased exercise tolerance accompanied by thrombocytopenia [31-35]. It has also been revealed that patients with a low preoperative SMI have less marked loss of SMI after esophagectomy [9]. Therefore, less marked loss of SMI after esophagectomy in patients treated with NAC may be attributed to a decrease in SMI during NAC.

Meanwhile, nutritional factors were not predictors for a change in SMI after surgery. In addition, unlike previous studies, progression of tumors was not a significant predictor of a change in SMI after esophagectomy in the present study. This may be because SMI in vulnerable elderly patients may be 
influenced by factors such as physical function and cognitive and social function compared with younger patients [36,37]. Regarding nutritional factors, we were not able to evaluate actual dietary intake and appetite. Stronger predictive indicators of a change in SMI may have been included in our analysis. Second, the statistical power was low because of the small sample size in the present study. Therefore, the impact of tumor progression and nutrition on changes in SMI in elderly patients after esophagectomy may be poor in the present study.

There are several limitations to the present study. First, causal relationships between outcomes and predictors were not guaranteed due to the retrospective observational nature of the study. Second, it is necessary to verify external validity due to the small sample size and the fact that the study was conducted at a single institution. Third, potential predictors that had a strong impact may not have been included in the analysis. We were not able to assess the amount of physical activity, dietary intake, and cognitive and social function owing to the retrospective nature of the study. Furthermore, the coefficient of determination $\left(R^{2}\right)$ for the multiple regression analysis was 0.26 , which indicated that the fit of the model was poor. In light of these limitations, we have to interpret the results carefully.

\section{Conclusion}

In the present study, we clarified predictors of a change in SMI in 54 elderly patients aged over 70 years with esophageal cancer after esophagectomy. Multiple regression showed that the independent predictors of a change in SMI 4 months after esophagectomy were a ratio change in isometric QS in the first month after esophagectomy and NAC. Supportive care and continuous comprehensive rehabilitation after esophagectomy might prevent loss of skeletal muscle mass after esophagectomy in elderly patients with esophageal cancer.

\section{Declarations}

\section{[Acknowledgments]}

The authors thank the members of the Department of Musculoskeletal Oncology and Rehabilitation, Esophageal Surgery, for their support; this research would not have been possible without their cooperation. We thank Emily Woodhouse, PhD, from Edanz Group (https://en-authorservices.edanz.com/ac) for editing a draft of this manuscript.

\section{[Funding]}

Nothing.

\section{[Conflicts of interest]}

The authors declare no potential conflicts of interest with regard to the research, authorship, or publication of this article. 


\section{[Ethics Approval]}

This study was approved by the research ethics committee of the National Cancer Center (2019-075) in accordance with the Declaration of Helsinki.

\section{[Consent to participate]}

Informed consent was obtained through an opt-out consent process.

\section{[Consent for publication (include appropriate statements) ]}

Not applicable.

\section{[Availability of data and materials]}

The participants of this study did not agree for their data to be shared publicly. The data of participants is not available.

\section{[Authors' Contributions]}

All authors contributed to the study conception and design. The first draft of the manuscript was written by $\mathrm{TH}$ and all authors commented on previous versions of the manuscript. All authors read and approved the final manuscript. Conceptualization: TH, NT, Takeo F, TT. Data collection and analysis: TH, NT, JU, YK, NK, HF, Takeo F. Writing-Reviewing and editing: TH, NT, Takuya F, Takeo F, AY, TT. Supervision: Takeo F, TT.

\section{References}

1. Tachimori Y et al (2016) Comprehensive Registry of Esophageal Cancer in Japan, 2009. Esophagus 13:110-137.

2. Cijs TM et al (2010) Outcome of esophagectomy for cancer in elderly patients. Ann Thorac Surg 90:900-907.

3. Tapias LF et al (2013) Short and long-term outcomes after esophagectomy for cancer in elderly patients. Ann Thorac Surg 95:1741-1748.

4. Takahashi K et al (2019) Prognostic significance of skeletal muscle loss during early postoperative period in elderly patients with esophageal cancer. Ann Surg Oncol 26:3727-3735.

5. Nakashima $Y$ et al (2018) Assessment of sarcopenia as a predictor of poor outcomes after esophagectomy in elderly patients with esophageal cancer. Ann Surg 267:1100-1104.

6. Pamoukdjian F et al (2017) Prevalence and predictive value of pre-therapeutic sarcopenia in cancer patients: a systematic review. Clin Nutr 37:1101-1113.

7. Strulov SS et al (2016) Prognostic value of sarcopenia in adults with solid tumours: a meta-analysis and systematic review. Eur J Cancer 57:58-67. 
8. Kudou K et al (2019) Postoperative skeletal muscle loss predicts poor prognosis of adenocarcinoma of upper stomach and esophagogastric junction. World J Surg 43:1068-1075.

9. Nakashima $Y$ et al (2019) Skeletal muscle loss after esophagectomy is an independent risk factor for patients with esophageal cancer. Ann Surg Oncol 27:492-498.

10. dos Santos $L$ et al (2017) Sarcopenia and physical independence in older adults: the independent and synergic role of muscle mass and muscle function. J Cachexia Sarcopenia Muscle 8:245-250.

11. Beaudart C et al (2015) Quality of life and physical components linked to sarcopenia: the SarcoPhAge study. Exp Gerontol 69:103-110.

12. Cruz-Jentoft AJ et al (2019) Sarcopenia: revised European consensus on definition and diagnosis. Age Ageing 48:16-31.

13. Auyeung TW et al (2014) Age-associated decline of muscle mass, grip strength and gait speed: a 4year longitudinal study of 3018 community-dwelling older Chinese. Geriatr Gerontol Int 14:76-84.

14. Delmonico MJ et al (2009) Longitudinal study of muscle strength, quality, and adipose tissue infiltration. Am J Clin Nutr 90:1579-1585.

15. Huang $Y$ et al (2015) Prognostic role of serum C-reactive protein in esophageal cancer: a systematic review and meta-analysis. Ther Clin Risk Manag 11:89-94.

16. Yang $X$ et al (2015) Prognostic significance of neutrophil-to-lymphocyte ratio in esophageal cancer: a meta-analysis. Onco Targets Ther 8:789-794.

17. Rice TW et al (2010) 7th edition of the AJCC Cancer Staging Manual: esophagus and esophagogastric junction. Ann Surg Oncol 17:1721-1724.

18. Katayama $\mathrm{H}$ et al (2016) Extended Clavien-Dindo classification of surgical complications: Japan Clinical Oncology Group postoperative complications criteria. Surg Today 45:668-685.

19. Tatematsu $\mathrm{N}$ et al (2013) Impact of oesophagectomy on physical fitness and health-related quality of life in patients with oesophageal cancer. Eur J Cancer Care 22:308-313.

20. Guralnik JM et al (1994) A short physical performance battery assessing lower extremity function: association with self-reported disability and prediction of mortality and nursing home admission. $J$ Gerontology 49:85-94.

21. Onodera T et al (1984) Prognostic nutritional index in gastrointestinal surgery of malnourished cancer patients. Journal of the Japanese Surgical Society 85:1001-1005.

22. Mourtzakis $\mathrm{M}$ et al (2008) A practical and precise approach to quantification of body composition in cancer patients using computed tomography images acquired during routine care. Appl Physiol Nutr Metab 33:997-1006.

23. Takayuki I et al (2016) Changes in exercise capacity, muscle strength, and health-related quality of life in esophageal cancer patients undergoing esophagectomy. BMC Sports Sci Med Rehabilitation 8:e34. https://org/10.1186/s13102-016-0060-y.

24. van Egmond MA et al (2020) The pre-and postoperative course of functional status in patients undergoing esophageal cancer surgery. Eur J Surg Oncol 46:173-179. 
25. Haight TJ et al (2013) Direct effects of leisure-time physical activity on walking speed. J Nutr Health Aging 17:666-673.

26. Massimiliano $P$ et al (2014) Effect of light and vigorous physical activity on balance and gait of older adults. Arch Gerontol Geriatr 59:568-573.

27. Foong YC et al (2016) Accelerometer-determined physical activity, muscle mass, and leg strength in community-dwelling older adults. J Cachexia Sarcopenia Muscle 7:275-283.

28. Gomez-Cabello A et al (2014) Age and gender, two key factors in the associations between physical activity and strength during the ageing process. Maturitas 78:106-112.

29. Rantanen $T$ et al (1997) Physical activity and the changes in maximal isometric strength in men and women from the age of 75 to 80 years. J Am Geriatr Soc 45:1439-1445.

30. Guinan EM et al (2019) Measuring the impact of oesophagectomy on physical functioning and physical activity participation: a prospective study. BMC Cancer 19:e682. https://org/10.1186/s12885-019-5888-6.

31. Kamitani $\mathrm{N}$ et al (2019) Association of skeletal muscle loss with the long-term outcomes of esophageal cancer patients treated with neoadjuvant chemotherapy. Surg Today 49:1-7.

32. Sunde B et al (2019) Health-related quality of life in a randomized trial of neoadjuvant chemotherapy or chemoradiotherapy plus surgery in patients with oesophageal cancer (NeoRes Trial). Br J Surg 106:1452-1463.

33. Jarvinen T et al (2018) Loss of skeletal muscle mass during neoadjuvant treatments correlates with worse prognosis in esophageal cancer: a retrospective cohort study. World J Surg Oncol 16:e27. https://doi.org/10.1186/s12957-018-1327-4.

34. Hiura $Y$ et al (2012) Fall in plasma ghrelin concentrations after cisplatin-based chemotherapy in esophageal cancer patients. Int J Clin Oncol 17:316-323.

35. Jack $S$ et al (2014) The effect of neoadjuvant chemotherapy on physical fitness and survival in patients undergoing oesophagogastric cancer surgery. Eur J Surg Oncol 40:1313-1320.

36. Chang KV et al (2016) Association between sarcopenia and cognitive impairment: a systematic review and meta-analysis. J Am Med Dir Assoc 17:1164.e7-1164.-e15.

https://org/10.1016/j.jamda.2016.09.013.

37. Hyuma $\mathrm{M}$ et al (2019) Associations of social frailty with loss of muscle mass and muscle weakness among community-dwelling older adults. Geriatr Gerontol Int 19:76-80.

\section{Tables}


Table 1 Patient characteristics

Age (years)

Sex (male/female $\rrbracket$

Neoadjuvant chemotherapy (with/without)

Upper/middle/lower

Squamous cell carcinoma/adenocarcinoma

Preoperative CRP ( $<0.5 \mathrm{mg} / \mathrm{dL}$ vs. $\geq 0.5 \mathrm{mg} / \mathrm{dL}$ )

Preoperative NLR $(<3.5 / \geq 3.5)$

Pathological stage (I-II/III)

Pathological T (1-2/3-4)

Pathological N (0/1-3)

Pathological M (0/1)

Complications (Clavien-Dindo classification $\geq$ Grade I)

Pneumonia

Anastomotic leak

Length of hospital stay ( $<18.5$ days vs. $\geq 18.5$ days)

Preoperative physical function and nutrition

Quadriceps muscle strength (N)

Usual gait speed $(\mathrm{m} / \mathrm{sec})$

PNI (score)

BMI $\left(\mathrm{kg} / \mathrm{m}^{2}\right)$ $n=54$

$75.3 \pm 3.6$

$42(78) / 12$ (22)

$29(54) / 25$ (46)

$2(4) / 48(89) / 4$ (7)

$2(4) / 52$ (96)

45 (83)/9 (17)

$43(80) / 11$ (20)

40 (74)/14 (26)

$33(61) / 21$ (39)

$32(59) / 22(41)$

54 (100)/0 (0)

$9(17)$

9 (17)

$27(50) / 27$ (50)

$399 \pm 124$

$1.17 \pm 0.21$

$47.9 \pm 4.1$

$21.1 \pm 3.0$

Change in physical function and nutrition in the first month after surgery

Quadriceps muscle strength (\%)

$-10.8 \pm 15.7$

Usual gait speed (\%)

$-4.0 \pm 16.2$

PNI (\%)

$-6.9 \pm 10.3$

BMI (\%)

$-8.0 \pm 3.7$

SMI

Preoperative SMI $\left(\mathrm{cm}^{2} / \mathrm{m}^{2}\right)$

$40.3 \pm 7.7$

Change in ratio of SMI after surgery (\%)

$-7.1 \pm 9.4$ 
Descriptive statistics are presented as number of people (\%) and mean \pm standard deviation. CRP: Creactive protein; NLR: neutrophil-lymphocyte ratio; pathological TNM stage (UICC $7^{\text {th }}$ edition); PNI: Onodera's prognostic nutritional index; BMI: body mass index; SMI: skeletal muscle mass index 
Table 2 Univariate and multivariate analysis for the ratio change in SMI after surgery

Variables

Univariate analysis

Multivariate analysis

$\mathrm{B}(95 \% \mathrm{Cl})$

$\mathrm{p}$

$\mathrm{B}(95 \% \mathrm{Cl})$

$\beta$

$\mathrm{p}$

Preoperative physical function and nutrition

\begin{tabular}{|c|c|c|}
\hline $\begin{array}{l}\text { Quadriceps muscle strength } \\
(\mathrm{N}) \text {, per } 1 \mathrm{~N}\end{array}$ & $\begin{array}{l}-0.020(-0.040 \\
\text { to } 0.000)\end{array}$ & 0.054 \\
\hline $\begin{array}{l}\text { Usual gait speed }(\mathrm{m} / \mathrm{sec}) \text {, } \\
\text { per } 0.1 \mathrm{~m} / \mathrm{sec}\end{array}$ & $\begin{array}{l}2.496(-9.772 \\
\text { to } 14.765)\end{array}$ & 0.685 \\
\hline PNI (score), per 1 score & $\begin{array}{l}-0.021(-0.666 \\
\text { to } 0.624)\end{array}$ & 0.948 \\
\hline BMI $\left(\mathrm{kg} / \mathrm{m}^{2}\right)$, per $1 \mathrm{~kg} / \mathrm{m}^{2}$ & $\begin{array}{l}-0.107(-0.968 \\
\text { to } 0.754)\end{array}$ & 0.804 \\
\hline
\end{tabular}

Postoperative change ratio in physical function and nutrition (first month after surgery)

Quadriceps muscle strength

(\%), per $1 \%$

0.167 (0.007 to $\quad \mathbf{0 . 0 4 1 *}^{*} \quad 0.169(0.010$

0.274

0.038 *

$0.327)$ to 0.318$)$

$\begin{array}{lll}\text { Usual gait speed (\%), per 1\% } \begin{array}{ll}-0.079(-0.239 & 0.325 \\ \text { to } 0.081)\end{array} & \end{array}$

PNI (\%), per $1 \%$

$0.131(-0.119 \quad 0.298$

to 0.382 )

BMI (\%), per $1 \%$
$0.514(-0.170$
to 1.198$)$
0.138

Patient characteristics

Neoadjuvant chemotherapy

(vs. without)

Age (years), per 1 year

Male (vs. female)

Preoperative SMI $\left(\mathrm{cm}^{2} / \mathrm{m}^{2}\right)$, per $1 \mathrm{~cm}^{2} / \mathrm{m}^{2}$

7.352 (2.580 to 12.125)

$$
\begin{aligned}
& -0.126(-0.851 \\
& \text { to } 0.599)
\end{aligned}
$$

-4.536
$(-10.634$ to
$1.562)$

$-0.200(-0.535$

to 0.135 )

0.237

0.142

0.729

(1)

$7.222(2.013$ to 12.430 )

0.263

$(-0.426$ to

0.953)
$0.387 \mathbf{0 . 0 0 8 *}$

$0.101 \quad 0.446$

$-4.647$

$(-11.473$ to

2.179)

0.099

0.694

$(-0.312$ to

0.465 )

pStage III (vs. I- II)

$$
\begin{aligned}
& -1.071(-6.671 \\
& \text { to } 4.830)
\end{aligned}
$$

$-0.969$

$(-6.391$ to

pT stage 3-4 (vs. 0-2)

$$
2.401(-2.868 \quad 0.365
$$




\begin{tabular}{|c|c|c|}
\hline pN stage $1-3$ (vs. 0) & $\begin{array}{l}-1.642(-6.891 \\
\text { to } 3.607)\end{array}$ & 0.533 \\
\hline $\begin{array}{l}\text { Preoperative CRP } \geq 0.5 \\
\mathrm{mg} / \mathrm{dL} \text { (vs. }<0.5 \mathrm{mg} / \mathrm{dL} \text { ) }\end{array}$ & $\begin{array}{l}6.126(-0.608 \\
\text { to } 12.861)\end{array}$ & 0.074 \\
\hline $\begin{array}{l}\text { Preoperative NLR } \geq 3.5 \text { (vs. } \\
<3.5 \text { ) }\end{array}$ & $\begin{array}{l}4.592(-1.708 \\
\text { to } 10.892)\end{array}$ & 0.150 \\
\hline Pneumonia grade $\geq 1$ (vs. 0) & $\begin{array}{l}2.263(-4.655 \\
\text { to } 9.181)\end{array}$ & 0.514 \\
\hline $\begin{array}{l}\text { Anastomotic leak grade } \geq 1 \\
\text { (vs. 0) }\end{array}$ & $\begin{array}{l}-3.142 \\
(-10.033 \text { to } \\
3.750)\end{array}$ & 0.365 \\
\hline $\begin{array}{l}\text { Hospital stay } \geq 18.5 \text { days } \\
\text { (vs. }<18.5 \text { days) }\end{array}$ & $\begin{array}{l}-0.669(-5.845 \\
\text { to } 4.506)\end{array}$ & 0.796 \\
\hline \multicolumn{3}{|c|}{$\begin{array}{l}\text { Multiple regression was used for the multivariate analysis of ratio change in SMI in } 54 \text { patients who } \\
\text { underwent esophagectomy. Multiple regression was performed with potential predictors detected by a } \\
\text { univariate analysis and confounding factors. The above categorical variables were analyzed as } \\
\text { dummy variables ( } 1 \text { vs. O). The multiple regression model was adjusted for age, sex, preoperative SMI, } \\
\text { and pStage. B: partial regression coefficient; Cl: confidence interval; } \beta \text { : standardized partial regression } \\
\text { coefficient; p: p value; PNI: Onodera's prognostic nutritional index; BMI: body mass index; SMI: skeletal } \\
\text { muscle mass index; pStage: pathological stage (UICC } 7^{\text {th }} \text { edition); pT and pN: pathological TNM stage } \\
\text { (UICC } 7^{\text {th }} \text { edition); CRP: C-reactive protein; NLR: neutrophil-lymphocyte ratio; grade: JCOG } \\
\text { postoperative complication criteria according to the Clavien-Dindo classification; *: } p<0.05\end{array}$} \\
\hline
\end{tabular}


Table 3 Logistic regression analysis of predictors

Variables

Massive decline in QS in the first month Treatment with NAC after surgery (-9.9\% and lower)

Odds ratio $(95 \% \mathrm{Cl})$

$\mathrm{p}$

Odds ratio $\quad \mathrm{p}$

$(95 \% \mathrm{Cl})$

Preoperative physical function and nutrition

\begin{tabular}{llllll}
$\begin{array}{l}\text { Quadriceps muscle } \\
\text { strength }(\mathrm{N}) \text {, per } 1 \mathrm{~N}\end{array}$ & $1.001(0.997$ to 1.006$)$ & 0.608 & $\begin{array}{l}0.998(0.994 \\
\text { to } 1.003)\end{array}$ & 0.400 \\
$\begin{array}{l}\text { Usual gait speed }(\mathrm{m} / \mathrm{sec}), \\
\text { per } 0.1 \mathrm{~m} / \mathrm{sec}\end{array}$ & $1.988(0.156$ to 2.386$)$ & 0.597 & $\begin{array}{l}3.882(0.289 \\
\text { to } 52.063)\end{array}$ & 0.306 \\
\hline PNI (score), per 1 score & $1.071(0.934$ to 1.228$)$ & 0.327 & $\begin{array}{l}0.980(0.858 \\
\text { to } 1.121)\end{array}$ & 0.772 \\
\hline BMI $\left(\mathrm{kg} / \mathrm{m}^{2}\right)$, per $1 \mathrm{~kg} / \mathrm{m}^{2}$ & $0.997(0.835$ to 1.191$)$ & 0.975 & $\begin{array}{l}0.818(0.671 \\
\text { to } 0.998)\end{array}$ & $\mathbf{0 . 0 4 7 *}$ \\
\hline
\end{tabular}

Postoperative change in physical function and nutrition (the

first month after surgery)

\begin{tabular}{|lllll|}
$\begin{array}{l}\text { Quadriceps muscle } \\
\text { strength (\%), per 1\% }\end{array}$ & - & - & $\begin{array}{l}1.012(0.977 \\
\text { to 1.049) }\end{array}$ & 0.492 \\
$\begin{array}{l}\text { Usual gait speed (\%), per } \\
\text { 1\% }\end{array}$ & $0.955(0.916$ to 0.996$)$ & $\mathbf{0 . 0 3 2 *}$ & $\begin{array}{l}0.982(0.949 \\
\text { to } 1.017)\end{array}$ & 0.316 \\
\hline PNI (\%), per 1\% & $0.963(0.911$ to 1.017$)$ & 0.178 & $\begin{array}{l}1.005(0.954 \\
\text { to } 1.059)\end{array}$ & 0.854 \\
\hline BMI (\%), per 1\% & $0.891(0.766$ to 10.037$)$ & 0.135 & $\begin{array}{l}1.032(0.893 \\
\text { to } 1.192)\end{array}$ & 0.674 \\
\hline
\end{tabular}

Patient characteristics

\begin{tabular}{|c|c|c|c|c|}
\hline $\begin{array}{l}\text { Neoadjuvant } \\
\text { chemotherapy (vs. } \\
\text { without) }\end{array}$ & $0.638(0.218$ to 1.874$)$ & 0.414 & - & - \\
\hline Age (years), per 1 year & 1.031 (0.887 to 1.197$)$ & 0.695 & $\begin{array}{l}0.867(0.737 \\
\text { to } 1.019)\end{array}$ & 0.084 \\
\hline Male (vs. female) & 1.000 (0.277 to 3.608$)$ & 1.000 & $\begin{array}{l}0.500(0.130 \\
\text { to } 1.917)\end{array}$ & 0.312 \\
\hline $\begin{array}{l}\text { Preoperative SMI } \\
\left(\mathrm{cm}^{2} / \mathrm{m}^{2}\right) \text {, per } 1 \mathrm{~cm}^{2} / \mathrm{m}^{2}\end{array}$ & 0.985 (0.918 to 1.056$)$ & 0.668 & $\begin{array}{l}0.907(0.837 \\
\text { to } 0.983)\end{array}$ & $0.017 *$ \\
\hline pStage III (vs. I-II) & $0.455(0.129$ to 1.600$)$ & 0.219 & $\begin{array}{l}1.206(0.354 \\
\text { to } 4.115)\end{array}$ & 0.764 \\
\hline pT stage $3-4$ (vs. $0-2)$ & 0.856 (0.286 to 2.558$)$ & 0.780 & $\begin{array}{l}3.393(1.051 \\
\text { to } 10.951)\end{array}$ & 0.041 \\
\hline
\end{tabular}




\begin{tabular}{|c|c|c|c|c|}
\hline pN stage $1-3$ (vs. 0) & 0.538 (0.179 to 1.618$)$ & 0.270 & $\begin{array}{l}1.444(0.482 \\
\text { to } 4.325)\end{array}$ & 0.511 \\
\hline $\begin{array}{l}\text { Preoperative CRP } \geq 0.5 \\
\mathrm{mg} / \mathrm{dL} \text { (vs. }<0.5 \mathrm{mg} / \mathrm{dL} \text { ) }\end{array}$ & $1.307(0.310$ to 5.509$)$ & 0.715 & $\begin{array}{l}3.659(0.684 \\
\text { to } 19.567)\end{array}$ & 0.129 \\
\hline $\begin{array}{l}\text { Preoperative NLR } \geq 3.5 \\
\text { (vs. <3.5) }\end{array}$ & 1.257 (0.333 to 4.748$)$ & 0.736 & $\begin{array}{l}0.660(0.174 \\
\text { to } 2.496)\end{array}$ & 0.540 \\
\hline $\begin{array}{l}\text { Pneumonia grade } \geq 1 \text { (vs. } \\
\text { 0) }\end{array}$ & $2.286(0.508$ to 10.291$)$ & 0.282 & $\begin{array}{l}1.094(0.259 \\
\text { to } 4.613)\end{array}$ & 0.903 \\
\hline $\begin{array}{l}\text { Anastomotic leak grade } \\
\geq 1 \text { (vs. 0) }\end{array}$ & 4.375 (0.817 to 23.424$)$ & 0.085 & $\begin{array}{l}1.094(0.259 \\
\text { to } 4.613)\end{array}$ & 0.903 \\
\hline $\begin{array}{l}\text { Hospital stay } \geq 18.5 \text { days } \\
\text { (vs. }<18.5 \text { days) }\end{array}$ & 4.000 (1.290 to 12.402$)$ & $0.016 *$ & $\begin{array}{l}2.125(0.715 \\
\text { to } 6.135)\end{array}$ & 0.175 \\
\hline \multicolumn{5}{|c|}{$\begin{array}{l}\text { Logistic regression models were used for univariate analysis of predictors. A decline in QS in the first } \\
\text { month after surgery ( }-9.9 \% \text { or more) and treatment with neoadjuvant chemotherapy (NAC). The } \\
\text { above categorical variables were analyzed as dummy variables ( } 1 \text { vs. } 0) \text {. Cl: confidence interval; } \beta \text { : } \\
\text { standardized partial regression coefficient; } p \text { : p value; PNI: Onodera's prognostic nutritional index; BMI: } \\
\text { body mass index; SMI: skeletal muscle mass index; pStage: pathological stage (UICC } 7^{\text {th }} \text { edition); } \text { PT } \\
\text { and pN: pathological TNM stage (UICC } 7^{\text {th }} \text { edition); CRP: C-reactive protein; NLR: neutrophil- } \\
\text { lymphocyte ratio; grade: JCOG postoperative complication criteria according to the Clavien-Dindo } \\
\text { classification; *: } p \text { value }<0.05\end{array}$} \\
\hline
\end{tabular}

\section{Figures}




\section{Inclusion: $\quad 76$ patients}

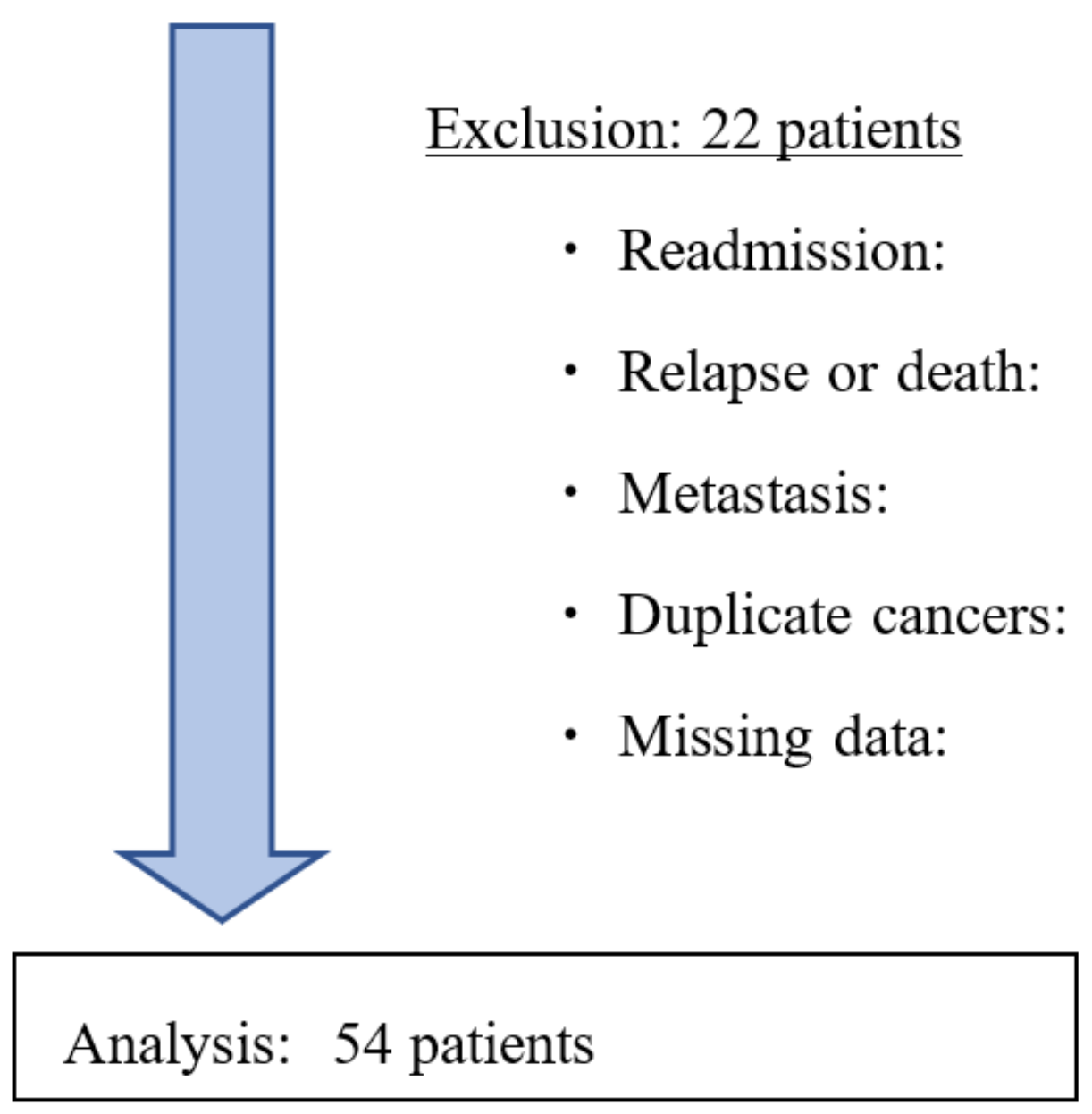

Figure 1

Recruitment flow diagram 
The association between change in SMI and QS (A)

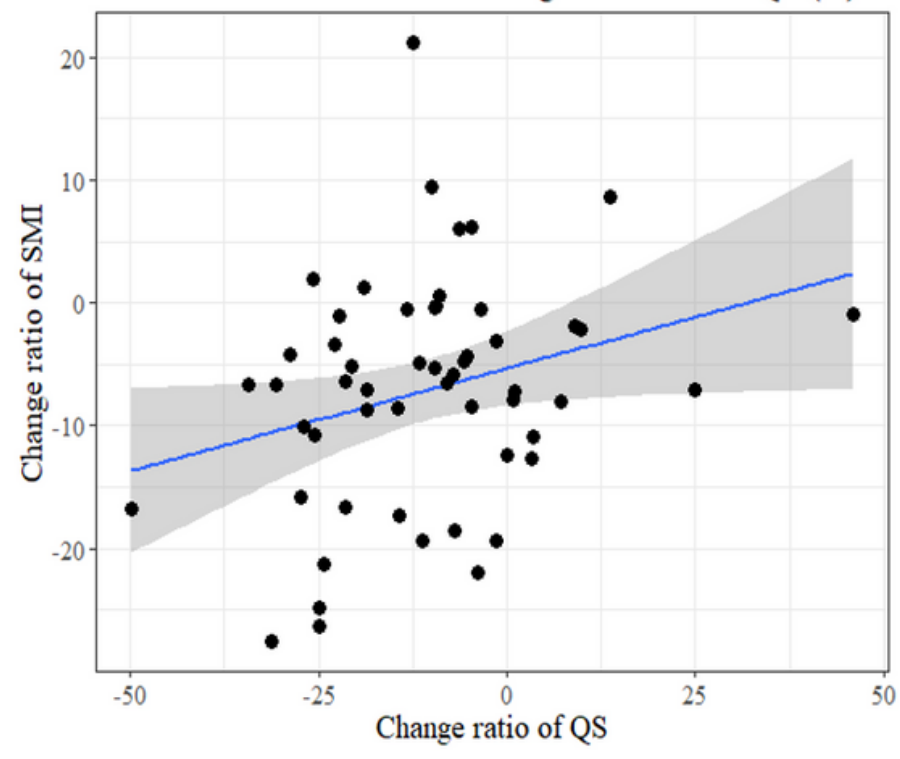

The stratified association by NAC (B)

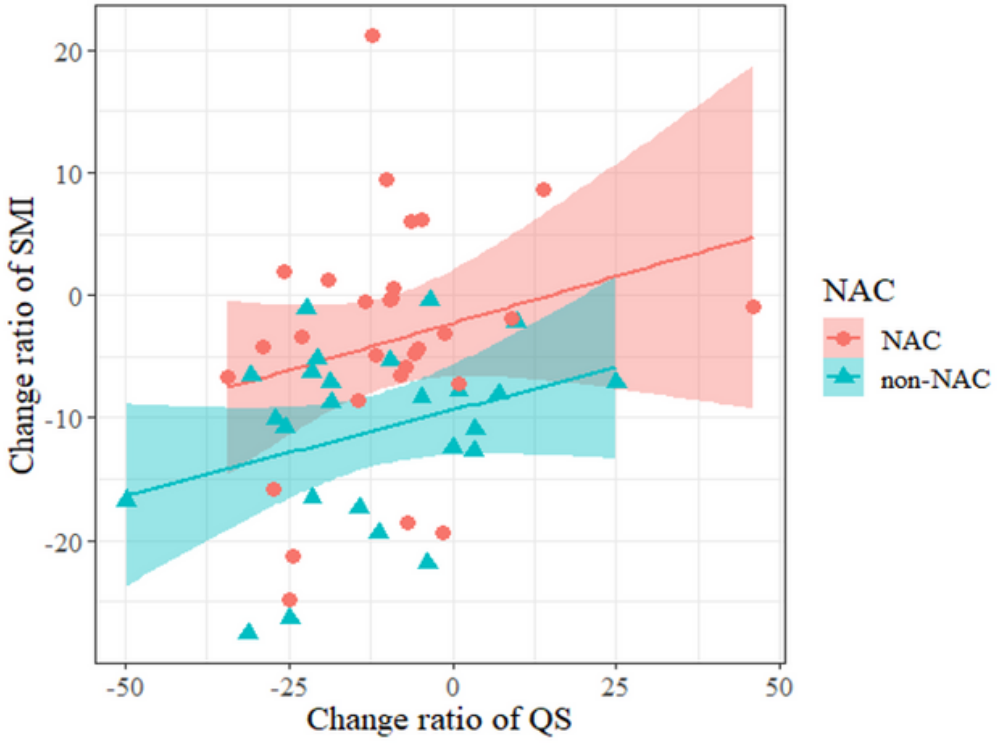

\section{Figure 2}

Association between the change in SMI 4 months after esophagectomy and quadriceps muscle strength in the first month after esophagectomy (left: A). Stratified association by NAC (right: B). The lines and area indicate linear regression and 95\% confidence intervals, respectively. QS: quadriceps muscle strength; NAC: neoadjuvant chemotherapy; SMI: skeletal muscle mass index

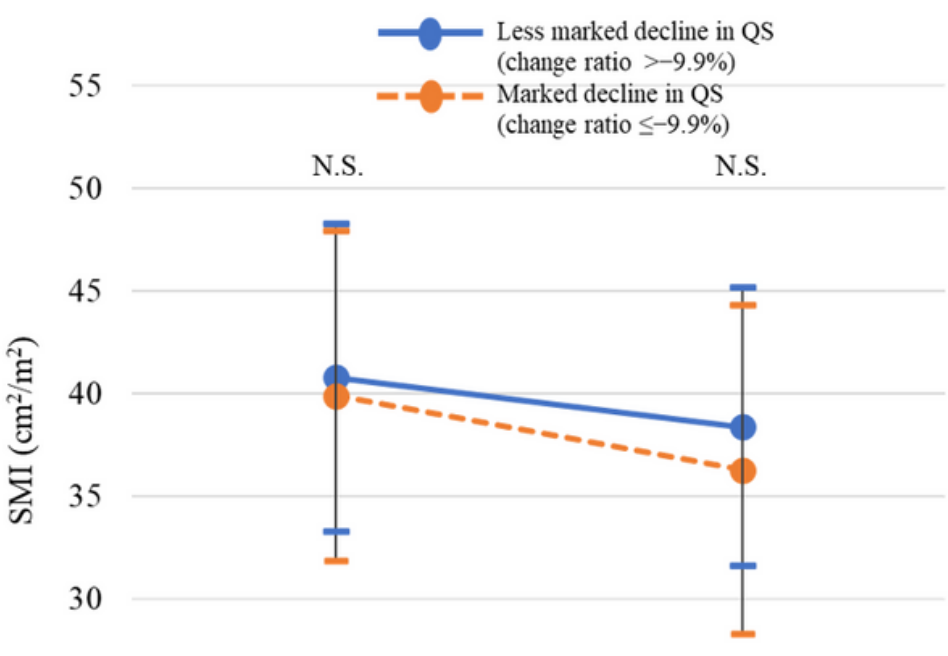

25
$4 \mathrm{M}$ after surgery

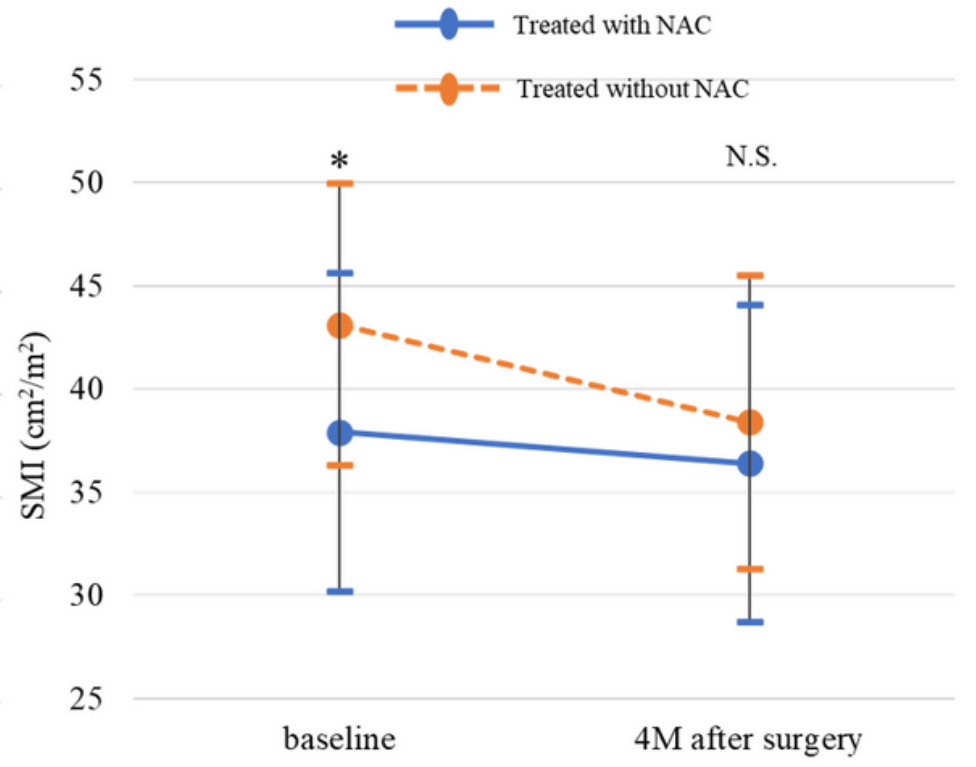

baseline

\section{Figure 3}

SMI (mean \pm standard deviation) at baseline and 4 months after surgery in two stratified groups: marked decline and minimal decline in quadriceps muscle strength (left). Treated with and without NAC (right). *: p < 0.05; N.S.: non-significant (analysis of variance adjusted with the Bonferroni method); QS: quadriceps muscle strength; NAC: neoadjuvant chemotherapy; SMI: skeletal muscle mass index 